\title{
A Predictive Study Of Parents Teachers' Association And Teachers Teaching Effectiveness In Yakurr Local Government Area Of Cross River State, Nigeria
}

\author{
${ }^{1}$ Dr. Martha Daniel Ekpe \& ${ }^{2}$ Dr. Eyong Emmanuel Ikpi \\ ${ }^{1}$ Department of Educational Management Faculty of Education Cross River University of Technology Calabar Cross River State, \\ ${ }^{2}$ Department of Educational Foundations and Childhood Education, Faculty of Education ,Cross River University of Technology Calabar Cross \\ River State, Nigeria \\ DOI: 10.29322/IJSRP.11.08.2021.p11611 \\ http://dx.doi.org/10.29322/IJSRP.11.08.2021.p11611
}

\begin{abstract}
The paper focused on predictive study of parents' teachers' association and teachers teaching effectiveness in Yakurr Local Government Area of Cross River State, Nigeria. In the course of the study, three (3) objective, research questions and hypotheses were formulated to guide the study and the study adopted the ex-post facto research design with a population of the 1682 primary six (6) pupils of public and private primary schools in Yakurr Local Government area of Cross River State, Nigeria The study adopted the stratified and simple random sampling techniques. In order to determine the sample size, a sample of 323 (19.3\%) was drawn using the Taro Yamane's formula and the instrument used for data collection is a researchers' validated instrument titled "Parent Teachers Association and Teachers Teaching Effectiveness questionnaire (PTATTEQ). Face validity was established by experts in Measurement and Evaluation and Elementary education respectively for adequate scrutiny of the items. In order to ascertain the reliability of the instrument a trial testing was carried out with 45 respondents who are not part of the sample schools. The reliability was established using Cronbach alpha reliability of internal consistency after the administration the reliability was calculated and the index ranged from 0.74 to 0.81 . The data was analyzed using descriptive and inferential statistics. The mean and standard deviation were used to test the research questions while simple linear regression analysis was adopted to answer the hypothesis as broken down below. Findings revealed that effective communication by PTA does significantly predict teachers teaching effectiveness. There was also a significant predictive influence of PTA professional advice on teachers teaching effectiveness. Finally, effective budgetary planning has a significantly predict teachers teaching effectiveness.
\end{abstract}

Index Terms- Predictive, Parents' Teachers' Association, Teaching Effectiveness and Yakurr,

\section{INTRODUCTION}

$\mathrm{T}$ he role of education most especially at the primary school cannot be underestimated. This is because the success of every child lies in the foundation and solidity of the kind and nature of education acquired at the primary school level. Little wonder, most students who are still struggling with most discipline in tertiary institution blame their ineptitude to poor foundation resulting from lack of quality primary education. To produce students (pupils), who can competently aspire political, social with economic self-reliance in this global village where the society today sees education the foundation for success tomorrow. To attain quality academic standard, there is need to focus more on the role of primary education, which can only be attained if parent are actively involved in the child's learning. It is a well-known fact that the burden of education of the child should not be left alone on the shoulder of the government and teachers. The place of the parent is inevitable to the overall success in the child's learning if academic excellence must be attained. This underscores the role of parents (Parents Teachers Association) in maintain effectiveness in teaching and learning process.

The need for teachers teaching effectiveness in any school cannot be compromised with. When there is quality in teaching there is likely to be effectiveness in the process and product of the school. Therefore, for any school to ascertain teaching effectiveness it must first and foremost involved stake holders who will bring the professional ideas (man power) that can help to build the school. This underscores the need for a well-established Parent Teachers Association (PTA). Parent Teacher's Association is one of the associations that participate strongly in educational management at all levels especially in primary and secondary schools in Yakurr Local Government Area of Cross River State Nigeria. If well established, they contribute drastically to the overall success of the school. The parent Teacher's Association today exists in almost every primary school in Nigeria as an ideal association whose contributions are channeled towards the management of education.

According to Ogbonnaya (2012), through PTA meetings, teacher and parents can learn about the classroom programmes which have been planned, the teacher will as well gain valuable insight into the child's relationship with parents in the home. Parents in some communities have been known to willingly levy themselves to make subscription towards the building of classroom, dormitories and laboratories. The parent Teacher's Association has participated immensely in the management of educations in Yakurr Local Government Area of Cross River State. One often comes across school buildings, school houses with the inscription donated by parent Teacher's Association times, without number, parents Teacher's Association request for the transfer of some principals or headmaster. Teachers finance 
clerk in their respective schools. According to Okwori (2013) opines that education brings about new changes at it relates to teaching and learning and most of the positive changes came as a result of the Parent Teacher's Association involvement in the provision of infrastructural facilities like classrooms, libraries among others. Also in the recruitment of teachers rendering of financial assistance and creating cordial relationship between schools and the host communities, parent's Teacher's Association plays a leading role for academic performance in Yakurr Local Government of Cross River State. According to Akpakwo (2012) said to ensure a coordinated education in the community, parent teachers association participate actively towards achieving to the goals or education. The participated conjunction with teachers in the education, there is need for constant monitoring, evaluation and appraisal by school Parent Teacher's Association.

According to Elui (2007), the goal of P. T. A. is to allow parents to know what is happening at school and to give their opinion on certain issues concerning children. The A. T. P. finances capital projects such as the construction of a new administrative block or classroom, the closing of the school, the provision of accommodation for staff, rooms for staff, There is a strong assertion that PTA represented as an association of parents and teachers who voluntarily come together to foster and enhance academic development.

In an empirical review by Kingi (2015) who sought to investigate the role of Parents' Teachers Association (PTA) in management of public secondary school in Gatundu North, Kiambu County. To accomplish this task survey method was used in conducting the study. A total of 13 schools out of 26 were selected comprising of 9 mixed secondary schools, 2 boys schools, and 2 girls secondary schools. Stratified random sampling technique and purposive sampling were employed to identify study sample. A questionnaire and interview guides were used for data collection. Qualitative and quantitative techniques were employed to data analysis. The study revealed the following challenges facing PTA in management of public secondary school: poor communication among staff, people and the community, shortage of staff personnel; inadequate school finances; misappropriations of funds, insufficient physical facilities; poor performance in national examinations; lack of support from the local community; and interference in the running of school by the local communities. In conclusion, urgent measures should be put in place so as to minimize the hindrances.

Ajayi, Ekundayo and Arogundade (2009) study examined the relationship between parents' involvement in school administration and effectiveness of secondary schools in Nigeria. The descriptive survey design was used for the study. The population consisted of all the teachers, principals and parents of the students in public secondary schools in South-West Nigeria. The sample comprised 1200 teachers, 300 parents and 60 principals from 60 secondary schools. Multi-stage, simple and stratified random sampling techniques were used to select the states, schools, teachers and parents used for the study. Two sets of questionnaire were used to collect the data for the study. The Data were analysed using frequency counts, percentage scores and Pearson product movement correlation. The only hypothesis formulated in the study was tested at 0.05 level of significance. The study revealed that parents were much involved in the administration of secondary schools in Nigeria. The study also revealed that secondary schools in the area covered were moderately effective. However, the study showed that there was no significant relationship between effective communication, parents' involvement in school administration and effectiveness in schools. It was recommended that the school administrators should sustain the high level of parents' involvement in school administration in order to maintain cordial relationship between the parents and the school authorities. Since parents' involvement in school administration was not significantly related to the effectiveness of the schools, the government and other stakeholders should make the teaching learning environment of the schools more conducive in order to improve their effectiveness The parents are more effective in imparting discipline and knowledge to students at the very grass root level. It is therefore a known fact that all parents have the natural inclination to give their children the good things of life they are capable of providing for them. And in the modern age, the major task is on the provision of quality education and good standard of living. In the light of this, parents have developed a very positive interest in what goes on in school. It is this interest of parents in the education of their children and wards in schools that gave birth to the organization or formation called "Parents Teachers Association.

In a study by Girma (2012) which focused on the practice of PTA in terms of professionalism among teachers in discharging its duties and responsibilities at Tsehay Mewcha Primary School in Delanta Worda, Amhara Region. This study included 37 participants of which 7 members were from PTA, 10 from teachers, 20 were from students of the upper grade level. The PTA members were selected using purposive sampling technique and the other teachers and students were selected using simple random sampling technique. The data were gathered through questionnaire, interview and focus group discussion and were analyzed quantitatively and qualitatively. The research finding indicates that PTA has helped most teachers to build professional development in their teaching and learning. It also identified the factors that affect PTA not to discharge its duties and responsibilities such as lack of training, knowledge, skill budget, attitudes, awareness, commitment and willingness, experience and shortage of time and ineffective professional skills were greater factors for failure of PTA. Furthermore, PTA did not get enough means of motivation, technical supports from the school leader. The research, therefore, recommends the solutions such as giving capacity building, promoting motivation system, and other technical supports from the school and other stake-holders to alleviate the problem.

Study by Ikuma (2014) examined the roles of the Parent Teacher Association (PTA) in primary schools in Nigeria. The state of primary schools in Nigeria suggests that there are still some problems facing the school in which the PTA had been found wanting. These include inadequate financial support of the PTA to the schools; lack of cooperation between the schools and the parents; inadequate supervision of schools among others. The purpose of this study also was to determine the contributions of the Parents Teachers Association to the Promotions of primary schools in Ekiti State as perceived by the headmasters. The study, which covered all the 261 headmasters in government-owned primary schools in Ekiti state, with particular reference to Ikere local government area, was based on two research questions and two null hypotheses. The survey design was adopted and a 
researcher-developed questionnaire was used to collect data. There was no sample rather, the entire 112 male and 149 female headmasters in the population, participated in the study. The researchers used 25-item questionnaire titled-Parents Teachers Association's promotions of Primary Schools Questionnaire (PTACPPSQ) to collect data from the headmasters with the help of three research assistants. Mean scores were used in answering the research questions while the z-test was used in testing all the null hypotheses. The findings of the study revealed that the in the perceptions of male and female headmasters, PTA contributed to school plant to a little extent, but made great extents of promotions and contributions to raising the moral tone of the school in terms of professional development. This finding would be of immense benefit to the government, parents and guardians, educational administrators, teachers, students and the society to evolve strategies for improving the contributions of the PTA in secondary education. Based on the findings, it was recommended among other things that the PTA and school principals should make concerted efforts to improve and sustain the promotions and contributions of the PTA in raising school's moral tones

Budgeting is a means of relating expenditure to the achievement of objectives. However, in breaking the budgetary process down, it can be seen that it also enables the organization to plan, coordinate, control and evaluate its activities. The budgetary process has four sets of components. The first component is planning; budgets are financial expressions in a quantified form of organizations activities.. A budget can demonstrate that the organization like a school plans to spend a certain amount on staffing or spend another amount on an extension to its buildings. It is therefore, a quantified plan for action. The parallel action to this is the How of communication. If planning is to achieve anything, then it has to be communicated and understood by all members of the organization.

Budgeting bring together a series of activities so that the amounts to be are organized in such a way that they contribute to meeting the organization's objectives. Organizations will fail unless the diverse set of expenditure - activities dealing with staffing, materials, equipment (to mention a few) are brought into focus by operational zing the plan so that it is managed to achieve its objectives. This management activity can and should be a major motivational tool. It is a means of involving staff in bringing together the school's activities so they have both the bigger picture and an understanding of how the parts fit together and their role in the activities.

Vadesto (2015) study intended to examine the effectiveness of secondary school budgets in implementation of school projects. The objectives of the study was to identify the school priorities when planning the school budgets, to find out challenges the secondary school experience in the budget planning and management and to analyze strategies to improve the budget planning and implementation in secondary schools. The population of this study was all secondary school teachers, DEO and all heads of schools in Sengerema Districts. The sample size consisted of 31 school teachers, school board members 30, Heads of school 4, DEO 1; a total of 66 respondents, the study used both structured questionnaire and interview to assess the realities of the study. Descriptive survey design helps to describe the information pertaining the effectiveness of school budget planning and management in schools. The findings revealed that $80 \%$ of school heads plan their school budget according to the needs of school and directives with guidelines from the central authority like the ministry of education and vocational training. The results from the study according to its objectives observed that $93 \%$ of the school administrators maintained their budget through considering the priorities which the government has planned for its uses. In addition, most of the heads of school suggested that capacity building through workshops, seminars is of prime importance in order to support their daily activities in area of procurement, bookkeeping, fund raising techniques, project planning and management. The study recommends that the heads of schools should continue to struggle for the acquisition of knowledge and skills necessary to facilitate their management in all areas by employing personal initiatives and through networking. It is on the basis of this foundation that the study sought to carry out a predictive study of Parent Teachers' Association and teachers teaching effectiveness in Yakurr Local Government area of Cross River State, Nigeria.

\section{PROBLEM STATEMENT}

The teacher is one who imbibes the right culture (character and learning) expected in the society to the student they teach. This means that for the teacher to be a professional in his/her chosen discipline effectiveness must be the watch word. When a teacher is ineffective, there is the likelihood that the students will also be ineffective in the learned materials. Teachers as role models are directly or indirectly being emulated by the students they teach. It is not gainsaying to inform that most teachers at the primary, secondary and even tertiary institutions are lacking the skills (pedagogical competencies) on how to effectively teach their subjects (students). The problem has become so serious that in most primary schools in Yakurr Local Government area of Cross River State, Nigeria most of the spend time doing petty businesses in their respective schools such as selling okrika, perfumes, inner wears, necklace, wrappers during school periods thereby, leaving their students at the mercies of the unknown. It is so disheartening to say that our children in the public school cannot competitively compete with their counterparts at the private schools in terms of quiz competitions. Even when most student at the public school strive to meet up academically, they seem to be half backed due to ill-professional teachers assigned to pilot the affairs of teaching. In most primary school, building, furniture, library and laboratory facilities are not provided to the pupils as reptiles have taken over most of our public primary schools. it hurts to say that our children now do not understand the need for quality education. No wonder there is high rate of indiscipline, truancy, cultism and lot of antisocial behaviours in our schools. Parents, teachers and the government are busy shifting blames to one another. Sorry to say that our government has actually lost focus in primary education in the society as most of them are busy playing politics with our educational system (future of the youths). The schools should see the urgent need of inculcating Parent Teachers Association (PTA) to effectively take control of our primary education so as to revamp the future of children who are believed to be the leaders of tomorrow. The problem of this study is thus; what is the predictive study of Parent Teachers' Association and teachers teaching effectiveness in Yakurr Local Government area of Cross River State, Nigeria.

This publication is licensed under Creative Commons Attribution CC BY

http://dx.doi.org/10.29322/IJSRP.11.08.2021.p11611

WWW.ijsrp.org 


\section{Purpose of the study}

The main purpose of the study is to Predictive study of Parent Teachers' Association and teachers teaching effectiveness in Yakurr Local Government area of Cross River State, Nigeria. Specifically, the study sought to

1. Examine how effective communication by PTA predict teachers teaching effectiveness

2. Determine the predictive influence of PTA professional advice and teachers teaching effectiveness

3. Ascertain the predictive influence of effective budgetary planning and teachers teaching effectiveness

\section{Research questions} study

The following research questions will be posed to direct the

1. To what extent doe effective communication by PTA predict teachers teaching effectiveness?

2. How does PTA professional advice predict teachers teaching effectiveness?

3. What is the predictive influence of effective budgetary planning and teachers teaching effectiveness?

\section{Statement of hypotheses}

1. Effective communication by PTA does not significantly predict teachers teaching effectiveness.

2. There is no significant predictive influence of PTA professional advice on teachers teaching effectiveness.

3. Effective budgetary planning does not significantly predict teachers teaching effectiveness.

\section{RESEARCH METHODOLOGY}

The study focused on predictive study of parent teachers' association and teachers teaching effectiveness in Yakurr Local Government Area of Cross River State, Nigeria. In the course of the study, three (3) objective, research questions and hypotheses were formulated to guide the study and the study adopted the expost facto research design with a population of the 1682 primary six (6) pupils of public and private primary schools in Yakurr Local Government area of Cross River State, Nigeria The study adopted the stratified and simple random sampling techniques. In order to determine the sample size, a sample of 323 (19.3\%) was drawn using the Taro Yamane's formula given below: $\mathrm{n}=\mathrm{N} /(1+\mathrm{N}$ (e)2. Where: $\mathrm{n}$ is the sample size. $\mathrm{N}$ is the population of the study. $\mathrm{e}$ is the margin error in the calculation. Apply this formula in the present study to select the sample size becomes.

$\mathrm{n}=\mathrm{N} /\left(1+\mathrm{N}(\mathrm{e})^{2}\right.$.

Sample $=1682 /\left(1+1682(0.05)^{2}\right.$ $=1682 /(1+1682(0.0025)$

$=1682 / 1+4.205$

$=1682 / 5.205$

$=1682 / 5.205$

$=323$

The instrument used for data collection is a researchers' validated instrument titled "Parent Teachers Association and Teachers Teaching Effectiveness questionnaire (PTATTEQ). Face validity was established by experts in Measurement and Evaluation and Elementary education respectively for adequate scrutiny of the items. In order to ascertain the reliability of the instrument a trial testing was carried out with 45 respondents who are not part of the sample schools. The reliability was established using Cronbach alpha reliability of internal consistency after the administration the reliability was calculated and the index ranged from 0.74 to 0.81 . The data was analyzed using descriptive and inferential statistics. The mean and standard deviation were used to test the research questions while simple linear regression analysis was adopted to answer the hypothesis as broken down below.

\section{RESULTS AND DISCUSSIONS}

This study focuses on an in-depth data analysis, presentation, interpretation, and discussion of the outstanding results of the study. Data analysis was done against the backdrop of the key study variables:

\section{General description of research variables}

The major independent variables of this study is PTA eeffective communication, professional advice and budgetary planning while the dependent variable in this study is teaching effectiveness, categorized in terms of lesson presentation and classroom management which are measured continuously. Results of the descriptive statistics are presented in Table 1.

TABLE 1

Descriptive statistics of PTA and teaching effectiveness $(\mathrm{N}=313)$

\begin{tabular}{llll}
\hline S/no & Variable & $\overline{\mathrm{X}}$ & SD \\
\hline 1 & Effective communication & 20.37 & 2.79 \\
2 & Professional advice & 18.45 & 3.62 \\
2 & Effective budgetary planning & 19.92 & 2.36 \\
8 & Teaching effectiveness & 21.02 & 3.01 \\
\hline
\end{tabular}

\section{Presentation of results}

The result emanating from the hypotheses tested and interpretation of findings including discussion of the outstanding results of the study are presented in this chapter. 


\section{Hypothesis one}

Effective communication by PTA does not significantly predict teachers teaching effectiveness. The predictive variable in this hypothesis is effective communication while the criterion variable is teaching effectiveness. To test this hypothesis, simple linear regression analysis was employed and the result is presented in Table 2.

Table 2: Simple linear regression analysis of effective communication by PTA and teachers teaching effectiveness

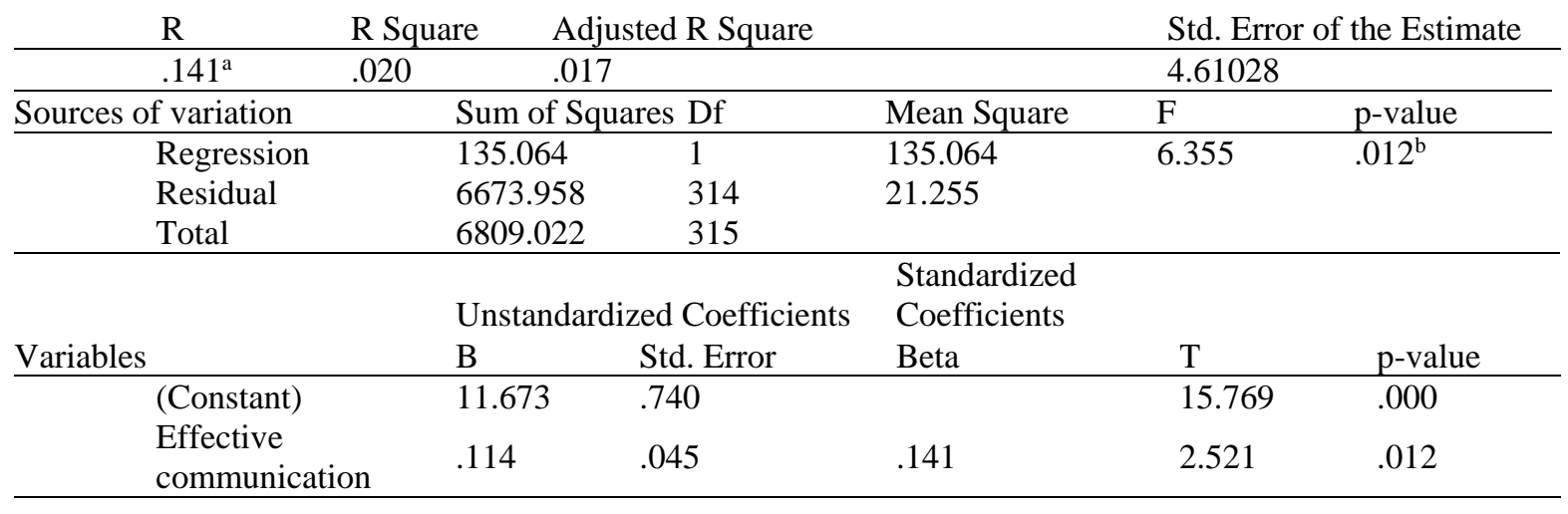

$* \mathrm{P}<.05$

Table 2 revealed that the p-value associated with the computed F-value (6.355) is less than the chosen alpha of .05. Hence, the null hypothesis is rejected. This implies that effective communication by PTA does significantly predict teachers teaching effectiveness.. The R-square of .020 means $20 \%$ of the variance in the criterion variable was accounted for by the predictive variable (effective communication). To test the significance of the combination of both the regression constant (11.673) and the regression coefficient (.114) to the prediction of effective communication, a t-test analysis was executed and the result as shown in Table 2 indicates that both variable (constant and effective communication. The mathematical relationship of the regression model is depicted by the following equation $\mathrm{y}=11.673+.114 \mathrm{x}$ where $\mathrm{y}=$ teaching effectiveness and $\mathrm{x}$ is effective communication.

\section{Hypothesis two}

There is no significant predictive influence of PTA professional advice on teachers teaching effectiveness. The predictive variable in this hypothesis is professional advise while the criterion variable is teaching effectiveness. To test this hypothesis, simple linear regression analysis was employed and the result is presented in table 3 .

TABLE 3: Simple linear regression analysis of professional advise by PTA and teachers teaching effectiveness

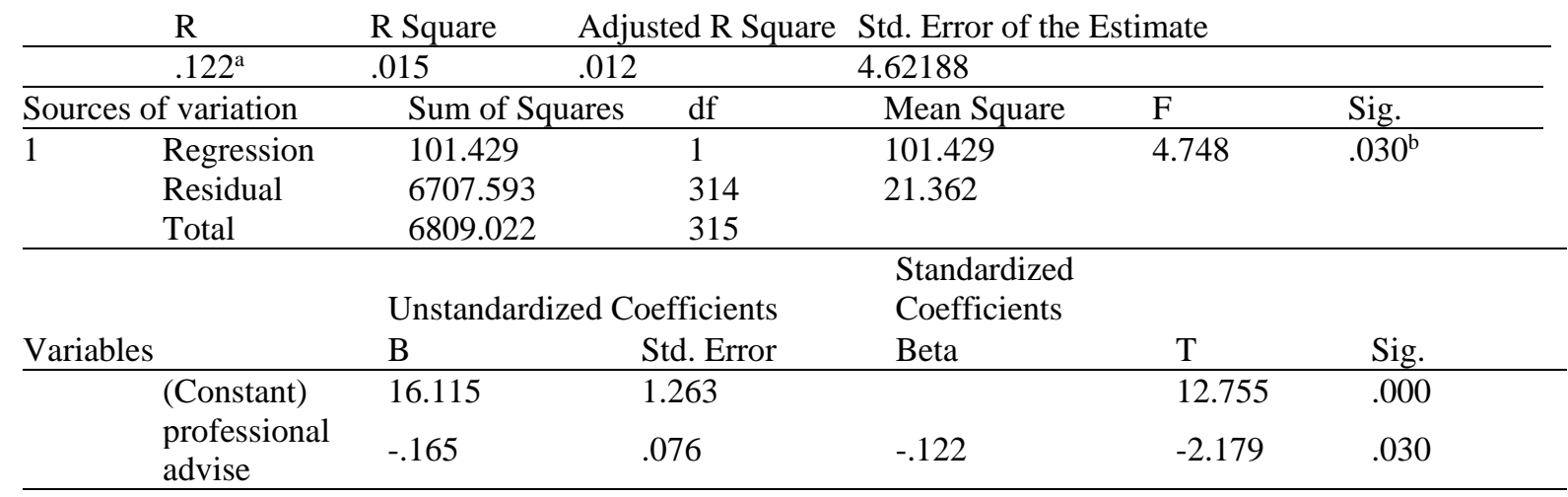

$* \mathrm{p}<.05$ 
Table 3 revealed that the p-value of .030 associated with the computed F-value (4.748) is less than the chosen alpha of .05. Hence, the null hypothesis is rejected. This implies that professional advise by PTA does significantly predict teachers teaching effectiveness. The R-square of .015 means $15 \%$ of the variance in the criterion variable was accounted for by the predictive variable professional advise). To test the significance of the combination of both the regression constant (16.115) and the regression coefficient (.165) to the prediction of professional advise, a t-test analysis was executed and the result as shown in Table 3 indicates that both variable (constant and effective communication. The mathematical relationship of the regression model is depicted by the following equation $y=16.115+.165 x$ where $\mathrm{y}=$ teaching effectiveness and $\mathrm{x}$ is professional advise.

\section{Hypothesis three}

Effective budgetary planning does not significantly predict teachers teaching effectiveness. The predictive variable in this hypothesis is budgetary planning while the criterion variable is teaching effectiveness. To test this hypothesis, simple linear regression analysis was employed and the result is presented in Table 4.

TABLE 4: Simple linear regression analysis of effective budgetary planning by PTA and teachers teaching effectiveness

\begin{tabular}{|c|c|c|c|c|c|}
\hline $\mathrm{R}$ & R Square & usted R Square & Std. Error of the & imate & \\
\hline $.116^{\mathrm{a}}$ & .013 & & 4.62522 & & \\
\hline Sources of variance & Sum of Squares & Df & Mean Square & $\mathrm{F}$ & p-value \\
\hline Regression & 91.723 & 1 & 91.723 & 4.288 & $.039^{\mathrm{b}}$ \\
\hline Residual & 6717.299 & 314 & 21.393 & & \\
\hline Total & 6809.022 & 315 & & & \\
\hline \multirow[b]{2}{*}{ Variables } & \multicolumn{2}{|c|}{ Unstandardized Coefficients } & $\begin{array}{l}\text { Standardized } \\
\text { Coefficients }\end{array}$ & & \\
\hline & $\mathrm{B}$ & Std. Error & Beta & $\mathrm{T}$ & $\mathrm{p}$-value \\
\hline $\begin{array}{l}\text { (Constant) } \\
\text { effective }\end{array}$ & 11.904 & .777 & & 15.315 & .000 \\
\hline $\begin{array}{l}\text { budgetary } \\
\text { planning }\end{array}$ & .096 & .046 & .116 & 2.071 & .039 \\
\hline
\end{tabular}

Table 4 revealed that the p-value of .039 associated with the computed F-value (4.288) is less than the chosen alpha of .05. Hence, the null hypothesis is rejected. This implies that effective budgetary planning by PTA does significantly predict teachers teaching effectiveness. The R-square of .016 means $16 \%$ of the variance in the criterion variable was accounted for by the predictive variable effective budgetary planning). To test the significance of the combination of both the regression constant (11.904) and the regression coefficient (.096) to the prediction of effective budgetary planning, a t-test analysis was executed and the result as shown in Table 4 indicates that both variable (constant and effective budgetary planning. The mathematical relationship of the regression model is depicted by the following equation $\mathrm{y}=16.115+.165 \mathrm{x}$ where $\mathrm{y}=$ teaching effectiveness and $\mathrm{x}$ is effective budgetary planning.

\section{DISCUSSIONS OF FINDINGS}

The findings of the study are discussed hypothesis by hypothesis as presented below

\subsubsection{Effective communication by PTA and teachers teaching effectiveness}

The finding revealed that effective communication by PTA has a significant relationship with teachers teaching effectiveness.
This result is not a surprise to the researchers because the total death of any association is poor communication flow from top to bottom and vice versa. When communication flows in the organisation there is bound to be free flow of information there is bound to be unity and understanding among workers in that organisation. Promoting such understanding and cooperation between teachers and parents would allow each party to contribute to the creation of an enabling atmosphere that will facilitate the learning and teaching process in schools The present finding agree with that by Kingi (2015) study revealed the following challenges facing PTA in management of public secondary school: poor communication among staff, people and the community, shortage of staff personnel; inadequate school finances; misappropriations of funds, insufficient physical facilities; poor performance in national examinations; lack of support from the local community; and interference in the running of school by the local communities. The present finding however disagrees with that by Ajayi, Ekundayo and Arogundade (2009) parents' involvement in school administration was not significantly related to the effectiveness of the schools, the government and other stakeholders should make the teaching learning environment of the schools more conducive in order to improve their effectiveness.

PTA professional advice and teachers teaching effectiveness

The finding revealed that PTA professional advice has a significant influence on teachers teaching effectiveness Thus, 
every teachers need professionalism to excel effectively in the teaching profession. The present finding is in harmony with Girma (2012) whose research finding indicates that PTA has helped most teachers to build effective professionalism in the teaching and learning process Ikuma (2014) findings of the study revealed that the in the perceptions of male and female headmasters, PTA contributed to school plant to a little extent, but made great extents of promotions and contributions to raising the moral tone of the school in terms of professional development. This finding would be of immense benefit to the government, parents and guardians, educational administrators, teachers, students and the society to evolve strategies for improving the contributions of the PTA in secondary education. Based on the findings, it was recommended among other things that the PTA and school principals should make concerted efforts to improve and sustain the promotions and contributions of the PTA in raising school's moral tones

\section{Effective budgetary planning and teachers teaching effectiveness}

The finding revealed that effective budgetary planning has a significant relationship teachers teaching effectiveness. Adequate funding of education plays a very crucial role in the provision of school physical facilities, teaching-learning resources, school personnel, school activities and programmes, which are indicators for measuring educational effectiveness and achievement. The finding agrees with Vadesto (2015) the findings revealed that $80 \%$ of school heads plan their school budget according to the needs of school and directives with guidelines from the central authority like the ministry of education and vocational training. The results from the study according to its objectives observed that $93 \%$ of the school administrators maintained their budget through considering the priorities which the government has planned for its uses.

\section{SUMMARY}

PTA is very paramount to the survival of every educational system, particularly at the primary and secondary school. Their numerous roles include planning, communication, professional advices, unity, peace and socio cultural harmony between the school and the community. Irrespective of their numerous advantages, there is need for a well defined role (aims and objectives). Th paper therefor, urge every stakeholders in the academic environment to encourage PTA by voluntary contribution, professional advise, planning the affairs of the school in corroboration with the school principals and head teachers and urging government to pay urgent attention to our primary school. It will be a failure to us and our generation yet unborn if we fold our arms ad watch the gradual decay of our primary education. The study has also deemed it important to share with every stakeholder in and outside the school environment that effective communication by PTA does significantly predict teachers teaching effectiveness. There was also a significant predictive influence of PTA professional advice on teachers teaching effectiveness and finally effective budgetary planning has a significantly predict teachers teaching effectiveness.

\section{RECOMMENDATIONS}

From the finding of the study, the following recommendations were drawn

1. PTA should create a solid platform which will enhance effective communication in all schools in the study area and beyond.

2. That PTA should ensure professionals in terms of inculcating educational administrator which will help to facilitate effective teaching and learning but not financiers of the school..

3. The inspectorate division of the Ministry of Education should be made functional to ensure strict adherence to standards and quality requirements in school administration, and standard instruction

\section{REFERENCES}

[1] Ajayi, I.A., Ekundayo T. H. \& Arogundade, B.B. (2009). Parents' involvement in school administration as a correlate of effectiveness of secondary schools in Nigeria. Journal of Education Administration and Policy Studies, 1 (3), 041-046.

[2] Elui, D. (2007). The Role of the Teachers in the school it impact and issues in Selected primary schools in Enugu state. International journal in research 2 (4) $27=35$

[3] Ikuma T. (2014). Assessment of PTA in primary schools in Nigeria. Education and research journal, 4(2) 1119.

[4] Akpakwo (2012). Parent Teachers Association (PTA) roles and funding of private school administration in Nigeria. Retrieved Teacher\%20Association $\% 20 \% 28 \mathrm{PTA} \% 29 \% 20$ in $\% 20$ discharging $\% 20$ its $\% 2$ 0Duties $\% 20$ and $\% 20$ Responsibilities.pdf? sequence $=1 \&$ isAllowed $=y 2 / 6 / 202$ 1.

[5] Federal .Republic .Nigeria (2004). National Policy on Education in Nigeria. NERDC PresS

[6] Girma, G. W. (2012). The Practice of Parent-Teacher Association( PTA) in Discharging Its Duties and Responsibilities At Tsehay Mewcha Primary School, Delanta Woreda, Amhara Rigion. Institute of Pedagogical Sciences Department of Educational Planning And Management Retrieved from https://opendocs.ids.ac.uk/opendocs/bitstream/handle/20.500.12413/6452/T he\%20Practice\%20of\%20Parent- 10th 062021

[7] Kingi, P. M. (2015). The Role of Parents' Teachers Association in the Management of Public Secondary School: Gatundu North, Kenya. International Journal of Science and Research (IJSR) 4 (9), 2102-2107.

[8] Ogbonnaya, Y. (2012). Home School Relationship as they Affect the Academic Success of Children. Education and Urban Society, 16,323 337.

[9] Okwori, K.L. (2013). "Redefining of School and Community Relations: Teachers' Perspective of Parents as Participants and Stakeholders" in Teacher Education Quarterly, pp. 12.

[10] Vadesto A. M. (2015). The Effectiveness of Secondary School Budgets in Implementation of School Projects in Sengerema District Mwanza. A Dissertation Submitted In Partial Fulfillment of The Requirements For The Degree Of Master Of Education In Administration, Planning and Policy Studies of The Open University of Tanzania. Retrieved from http://repository.out.ac.tz/1423/1/MGENI_MWANZA_SENGEREME_RE PORT_0753715592.pdf 17/7/2021

\section{AUTHORS}

First Author - Dr. Martha Daniel Ekpe, Department of Educational Management Faculty of Education Cross River University of Technology Calabar Cross River State

Second Author - Dr. Eyong Emmanuel Ikpi, Department of Educational Foundations and Childhood Education, Faculty of 
International Journal of Scientific and Research Publications, Volume 11, Issue 8, August 2021 ISSN 2250-3153

Education ,Cross River University of Technology Calabar Cross

River State, Nigeria 